\title{
MENGEMBANGKAN BISNIS DESAIN GRAFIS
}

\author{
Irwan Harnoko \\ Jurusan Desain Komunikasi Visual, Fakultas Komunikasi dan Multimedia, Bina Nusantara University \\ Jln. K.H. Syahdan No. 9, Palmerah, Jakarta Barat 11480
}

\begin{abstract}
Developing graphic design business needs promotion materials, some of them are newsletter, business card, Credit Line, and protofolio. Article explores the strategy of making newsletter, how to make business card to be professional, how to get the credit line, and how to make a portofolio, and what media that is able to clearly clarify the portofolio. It is concluded that people need extra ordinary creativity to achieve a successful in graphic design business.
\end{abstract}

Keywords: business, graphic design, newsletter, business card, credit line, portofolio

\begin{abstract}
ABSTRAK
Mengembangkan bisnis desain grafis memerlukan materi promosi, diantaranya Newsletter, (bagaimana strategi membuat newsletter), kartu Nama (bagaimana kartu nama tersebut terlihat profesional), Kredit Line (bagaimana mendapatkan kredit line), dan Portofolio (Apa saja media yang dipakai saat ini untuk menyajikan portofolio tersebut). Artikel menjelaskan bagaimana strategi membuat newsletter, bagaimana tampilan kartu nama agar terlihat professional, bagaimana mendapatkan kredit line, bagaimana membuat portofolio yang baik dan media apa saja yang cocok bagi portofolio. Disimpulkan, dibutuhkan kreativitas yang sangat luar biasa agar kita berhasil dalam dunia bisnis desain grafis.
\end{abstract}

Kata kunci: bisnis, desain grafis, newsletter, kartu nama, kredit line, portofolio 


\section{PENDAHULUAN}

Pada setiap tahap dalam bisnis desain grafis, pemberitahuan dari mulut ke mulut adalah salah satu cara yang paling efektif untuk mendapatkan lebih banyak pekerjaan. Dalam dunia marketing hal tersebut disebut Buzz Marketing. Kita harus menciptakan buzz (dalam arti positif tentunya) agar karya yang kita buat dibicarakan banyak orang, terutama orang atau perusahaan yang nantinya berpotensi menjadi klien kita. Bila Anda seorang desainer grafis yang berwirausaha dan bertanya bagaimana menciptakan buzz tersebut? maka tidaklah mengherankan Makki (2004) mengatakan, "If you think you know everything there is to know about starting up your own design business, well... think again!” Artikel membahas beberapa cara untuk mencapai tujuan tersebut berdasarkan studi pustaka yang telah penulis lakukan.

\section{PEMBAHASAN}

\section{Mengirimkan Newsletter}

Klien, teman, dan keluarga kita akan selalu ingat pada kita ketika seseorang berkata, "Apakah Anda tahu seseorang yang dapat mendesainkan kartu nama saya?" Sayangnya, manusia cepat lupa, bahkan saat mereka bermaksud baik. Solusinya? Ingatkan mereka! Mengirimkan newsletter kuartal (triwulanan) akan membuat Anda, dan bisnis desain, terdengar segar di pikiran mereka. Sertakan link mengenai pekerjaan yang baru-baru ini Anda kerjakan di Website dan berita tentang pekerjaan baru. Milis Anda harus menyertakan semua orang yang Anda tahu,misalnya klien, teman, keluarga, pekerja lepas, dll. kecuali jika mereka meminta untuk tidak disertakan. Anda tidak akan pernah tahu siapa yang akan memberikan Anda pekerjaan selanjutnya!

\section{Cara Membuat Email Newsletter}

\section{Mengumpulkan Kontak}

Email newsletter merupakan alat yang penting bagi pertumbuhan bisnis desain grafis. Ini adalah salah satu cara paling efektif untuk menyebarkan dari mulut ke mulut tentang jenis pekerjaan yang Anda lakukan dan cari. Berikut ini apa yang diperlukan untuk membuat dan memelihara email newletter.

Jika Anda akan mengirimkan newsletter, harus jelas dulu Anda mau mengirimkannya ke mana. Bahkan jika baru saja mulai, sebaiknya Anda sudah memiliki sebuah kelompok kecil yang dapat diirimi milis. Anda harus menyertakan klien, keluarga, teman, rekan kerja saat ini dan dulu, desainer grafis lain (dan illustrators, fotografer, dll), teman sekelas. Kecuali, jika seseorang meminta untuk tidak disertakan, ada baiknya jika Anda menyertakan setiap alamat email yang Anda peroleh, karena Anda tidak tahu siapa yang akan memberi Anda pekerjaan berikutnya.

\section{Mengatur dan Memelihara Kontak}

Setelah mengumpulkan daftar kontak, penting untuk tetap membuat kontak itu up-to-date dan terorganisir. Bagaimana Anda melakukan hal ini, bisa jadi tergantung pada software atau website apa yang Anda gunakan untuk mengirimkan newsletter Anda, karena biasanya paling mudah menggunakan buku alamat yang dibangun pada sistem tersebut. Layanan online perpesanan seperti Yahoo dan Google dan juga paket software seperti Outlook dan Mail (di Mac) semuanya memiliki cara untuk mengatur kontak Anda. Pastikan untuk memasukkan semua informasi yang Anda miliki, seperti nama lengkap dan alamat mailing Anda, dan untuk menambahkan kontak baru seketika setelah Anda mendapatkannya. 


\section{Menentukan konten}

Newsletter harus membantu mengingatkan masyarakat tentang layanan yang Anda tawarkan dan untuk menunjukkan layanan pada pekerjaan tersebut, dan harus meliputi konten berikut:

\section{Subjek}

Subjek email merupakan hal pertama yang akan dilihat oleh orang yang Anda kirimi. Sertakan nama Anda (atau nama perusahaan), istilah yang jelas agar mereka tahu bahwa itu merupakan newsletter, dan jika Anda mau, berikan perkenalan yang sangat singkat yang memberitahukan apa yang tercakup pada "edisi" kali ini. Contoh subjek yang baik (untuk perusahaan khayalan " Creative Design") adalah: "Yang terbaru di Creative Design: Desain Buku dan Pengemasan CD.”

\section{Pendahuluan}

Pendahuluan newsletter Anda harus singkat dan to the point, sebagai sambutan dan gambaran singkat mengenai apa pekerjaan Anda.

\section{Pekerjaan Baru-baru ini}

Ini adalah komponen kunci untuk newsletter Anda. Daftarlah pekerjaan yang baru-baru ini telah Anda selesaikan, dengan penjelasan singkat dan link atas contoh pekerjaan tersebut pada portofolio online (yang harus dimiliki oleh semua desainer grafis).

\section{Projek Berikutnya}

Jika ada, sertakan projek berikutnya sehingga orang yang Anda kirimi tahu bahwa Anda bahkan punya lebih banyak lagi pekerjaan yang sedang dalam proses.

\section{Penutup}

Akhiri dengan penutup yang singkat. Sertakan nama Anda (atau nama perusahaan), info kontak dan URL website. Katakan bahwa ada lebih banyak lagi hasil karya Anda yang tersedia secara online (jika ini masalahnya). Baik juga jika Anda mengucapkan terima kasih kepada klien atau siapa saja yang merekomendasikan suatu pekerjaan pada Anda, jika Anda ingin menambahkan sentuhan pribadi.

\section{Memformat Konten}

Bagaimana memformat konten (cara menampilkannya ke audiens Anda) mungkin juga akan ditentukan oleh sistem apa yang anda gunakan dalam mengirim newsletter Anda. Jika Anda tahu beberapa HTML dan ingin memformat newsletter Anda dengan cara itu, sebagian besar program email akan mendukung hal itu, tetapi jangan lupa untuk menguji milis Anda dulu ke beberapa kontak menggunakan layanan mail yang berbeda. Anda mungkin bahkan menggunakan HTML untuk langsung memasukkan beberapa gambar dalam email, tapi sekali lagi, hal itu harus diuji.

Semakin rumit desain Anda, semakin banyak masalah yang timbul saat Anda menampilkan newsletter Anda dalam berbagai program software dan situs web. Jika Anda ingin menampilkannya dengan sederhana, gunakan format seperti menulis dengan huruf besar untuk semua huruf pada judul guna memisahkannya dari konten. Apapun metodenya, penting bahwa newsletter tersebut mudah untuk dipindai (di-scan) dan dibaca. 


\section{Kirimkan}

Sekarang setelah Anda membuat dan memformat konten Anda, saatnya untuk mengirim newsletter ke daftar kontak Anda. Pastikan untuk mengujinya dulu (ke alamat Anda sendiri dan beberapa alamat lain), dan setelah Anda yakin bahwa newletter itu akan tampil dengan benar di berbagai platform email, tekan tombol kirim!

Ada paket software dan layanan online yang membuat seluruh proses itu jadi lebih mudah, jika anda mau berinvestasi di newsletter Anda. MaxBulk Mailer adalah paket Mac Software yang membantu Anda mengatur daftar kontak dan mengirim email dalam format HTML. Emma merupakan layanan online yang menawarkan desain template dan data statistic rinci untuk melacak siapa saja yang menerima, membuka dan meng-klik link di newsletter Anda. Itu tadi hanyalah beberapa dari banyak sekali pilihan.

Keputusan akhirnya adalah menentukan seberapa sering mengirimkan newsletter Anda. mengirimkannya setiap kuartal (triwulanan) akan menjadikan anda tetap segar dalam ingatan orang tanpa terkesan menjengkelkan. Jika kurang dari itu, maka resikonya adalah orang lain tidak akan mengingat Anda saat mereka ditanya apakah mereka kenal seorang desainer atau tidak. Jika Anda punya banyak pekerjaan, coba kirimkan lebih sering, tetapi lebih dari satu kali dalam satu bulan mungkin terlalu banyak. Tidak peduli seberapa sering Anda kirimkan, mailing newsletter secara konsisten merupakan cara untuk mendapatkan lebih banyak pekerjaan dan menjaga kontak Anda tetap up-to-date dalam bisnis desain.

\section{Kartu Nama}

Entah Anda seorang pekerja lepas atau Anda memiliki firma desain sendiri, sangat penting memiliki kartu nama untuk usaha desain grafis. Pertama kita akan melihat kelebihan memiliki kartu nama tersebut, dan kemudian beralih ke keputusan yang harus dibuat dan proses desain yang sebenarnya.

\section{Terlihat Profesional}

Alasan yang paling jelas dalam memiliki kartu nama desain grafis adalah agar dapat dengan mudah memberikan informasi kontak Anda kepada calon klien dan pemberi kerja. Anda pasti tidak ingin ketinggalan situasi yang tepat dalam mempromosikan bisnis Anda, kemudian mencari kertas untuk mencatat nomor telepon, alamat email dan situs web. Membawa kartu setiap saat akan memastikan bahwa Anda memberikan informasi yang akurat dan jelas pada orang lain. Penting sekali terlihat profesional dan sah, dan kartu nama merupakan langkah pertama.

\section{Pamerkan Hasil Kerja Anda}

Sebuah kartu nama bisa menjadi portfolio mini ... contoh pertama pekerjaan desain Anda yang Anda tunjukkan pada klien potensial. Desain, dan pesan dari kartu itu sendiri bisa tetap melekat dalam pikiran orang lain dan meyakinkan mereka untuk menghubungi Anda untuk proyek besar mereka selanjutnya. Kartu itu harus mencerminkan gaya pribadi Anda sendiri, jadi orang bisa sekilas melihat hasil pekerjaan Anda yang membuat mereka ingin melihat lebih banyak lagi. Bukan berarti kartu nama berdesain sederhana tidak dapat melakukan trik ini, bahkan hasil desain dasar dapat memberikan sedikit sentuhan yang bisa mengesankan klien Anda berikutnya.

\section{Isi Kartu Nama}

Sebelum mengerjakan desain kartu yang sebenarnya, tentukan apa yang ingin Anda cantumkan di dalamnya. Paling umum, sebuah kartu nama desain grafis akan berisi nama perusahaan, 
seperti logo, slogan, nama Anda (jika berbeda dengan nama perusahaan), judul atau deskripsi pekerjaan yang disediakan (yakni Web dan Desain Cetak), nomor telepon, nomor fax, alamat email, dan alamat website portfolio.

Jika konten tersebut di atas tercantum semua dalam kartu Anda, bisa jadi akan terlihat berlebihan dan terlalu padat pada ruang kecil kartu tersebut. Hanya sertakan hal-hal yang sangat penting saja. Bersama dengan hal-hal tersebut, pertimbangkan untuk menyertakan pesan yang bisa mewakili anda menyampaikan pesan pada target audien Anda.

\section{Cari Printer}

Anda tidak perlu harus memilih printer sebelum Anda mendesain kartu. Namun, mungkin akan membantu jika Anda melihat ukuran, kertas dan pilihan pada pencetakan lainnya lebih awal pada proses desain. Pastikan kualitas adalah apa yang Anda cari sesuai dengan anggaran Anda.

\section{Pilih Ukuran, Bentuk, dan Kertas}

Standar kartu nama adalah sepanjang 2 inci dengan lebar 3,5 inci. Ini biasanya adalah pilihan terbaik, karena akan cukup untuk dimasukkan dalam tempat kartu nama dan bersisian dengan kartu nama lainnya, dan seringkali membutuhkan biaya cetak terendah. Mungkin Anda memiliki desain yang akan sangat cocok sekali dituangkan pada kartu nama persegi atau lingkaran. Sebagian besar printer memang menyediakan berbagai bentuk dan ukuran, serta pemotong pinggir biasa. Ingatlah bahwa saat Anda ingin membuat pernyataan dengan bentuk yang keren, kartu itu harus nyaman, baik untuk Anda yang membawanya maupun untuk orang lain untuk mengambilnya, dan mudah-mudahan menyimpannya. Jangan membuat kesalahan dengan memilih bentuk dengan fungsi yang berlebihan. Memilih ukuran standar tetapi dengan sudut dibulatkan atau dibuat persegi bisa jadi sentuhan dan kompromi yang baik. Pada tahap ini, anda juga harus memutuskan apakah kartu tersebut digunakan satu atau kedua sisinya. Sebelum Anda menyelesaikan proyek kartu nama, Anda juga harus memilih kertas. Hal ini dibatasi oleh apa saja pilihan yang tersedia pada printer. Umumnya pilihannya adalah glossy dan matte dengan grammature yang berbeda. Sekali lagi, mendapatkan contoh dari printer dapat membantu dalam melakukan keputusan ini.

\section{Desain Kartu Anda}

Desainlah kartu Anda seolah-olah Anda sedang mengerjakan sebuah projek dari klien top Anda. Sekarang setelah Anda mengumpulkan konten dan menentukan ukurannya, beralihlah ke sketsa awal. Tentukan di mana saja setiap hal yang akan muncul pada kartu. Apakah Anda ingin satu sisi kartu hanya berisi logo, dengan informasi kontak di belakang? Apakah Anda ingin memberikan pesan pemasaran yang cerdas pada satu sisi dan semua informasi tentang perusahaan di sisi yang lain? Rencanakan ide Anda untuk membantu Anda membuat keputusan penting ini.

\section{Selalu Bawa Kartu Anda Ke mana Saja}

Sekarang setelah Anda sudah memasukkan semuanya ke dalam kartu nama Anda, pastikan Anda selalu membawanya ke manapun! Jangan ragu untuk memberikannya pada orang lain, dan kemudian biarkan hasil kerja keras dan desain Anda yang melakukan sisanya.

\section{Dapatkan Kredit Line Anda}

Salah satu cara terbaik untuk menjadikan nama Anda terkenal di luar adalah dengan menampilkannya pada sesuatu! Dalam beberapa kasus, kredit line bisa jadi tidak sesuai (di kartu nama, misalnya). Sebaliknya, jangan takut untuk meminta kredit line pada klien, atau memasukkannya 
pada kontrak Anda. Website harus menyertakan link Anda di bagian bawah (dari setiap halaman, jika mungkin), dan lembar cetak harus menyertakan nama Anda di suatu tempat dalam cetak kecil. Pilihan terbaiknya adalah dengan mencetak alamat web di lembar tercetak, jadi orang bisa langsung menuju ke situs Anda tanpa harus meminta info kontak Anda pada klien Anda atau mencari Anda melalui google dan berakhir di tempat yang salah. Hal sesederhana seperti "Didesain oleh myurl.com" akan benar-benar membantu.

\section{Bagaimana dan Mengapa meletakkan Kredit Line Anda pada Projek Desain Grafis}

Meletakkan kredit line desain grafis Anda pada hasil pekerjaan Anda merupakan cara terbaik untuk menyebarkan bisnis Anda. Hal ini memuaskan, dan menguntungkan, bila seseorang melihat hasil karya Anda dan menghubungi Anda untuk mengerjakan suatu proyek. Dalam banyak kasus, klien mungkin akan memberikan info kontak Anda pada orang lain sebagai informasi, tetapi sebaiknya jangan mengandalkan hal itu saja dan pastikan kalau orang lain dapat menghubungi Anda. Selain itu, tentu saja merupakan hal yang menyenangkan menempatkan kredit bila diijinkan dan melihat nama Anda pada karya desain jadi Anda.

\section{Bagaimana Anda Mendapatkan Kredit Line Desain Grafis}

Kemungkinan besar, klien tidak akan menyarankan Anda untuk menambahkan elemen pada proyek mereka dengan menyertakan kredit line. Namun, banyak juga yang tidak akan berkata "tidak" jika Anda katakan pada mereka kalau Anda ingin menyertakannya... begitulah langkah pertamanya. Jangan tanya klien apakah hal itu dapat mereka terima. Sebaliknya, sebutkan bahwa Anda akan menyertakan kredit line pada jenis proyek yang sedang Anda kerjakan (jika itu masalahnya), dan membiarkan mereka mempertimbangkannya. Akhirnya semua kembali pada Anda sendiri mengenai seberapa penting kredit line itu bagi Anda. Jika klien tidak menginginkannya, dan memiliki alasan yang logis, jangan sampai hal ini merusak kesepakatan Anda dengan mereka. Apakah Anda percaya klien akan merekomendasikan Anda jika seseorang menanyakan siapa yang mendesain karya itu? Jika demikian, Anda mungkin oke-oke saja. Setelah Anda melakukan perjanjian mengenai kredit line, apa yang akan tertulis, dan di mana akan diletakkan, harus Anda sertakan dalam kontrak.

\section{Kapan Anda Tidak Boleh Menyertakan Kredit Line}

Ada beberapa situasi di mana meletakkan kredit line desain grafis tidaklah sesuai. Yang paling umum adalah pada benda kecil seperti kartu nama, di mana menambahkan kredit line akan benarbenar merusak desain. Ia juga mungkin tidak akan berguna pada desain yang sangat minim, di mana kredit Anda akan menjadi satu-satunya elemen pada halaman tersebut. Seharusnya kredit line dipadukan dengan desain daripada berdiri sendiri. Kredit line sesuai bila diletakkan dalam proyek yang berskala lebih besar seperti desain buku atau pengemasan CD, di mana sering ada sebuah halaman yang didedikasikan untuk kredit dan "ucapan terima kasih." Pertimbangkan apakah Anda harus menyertakannya atau tidak.

\section{Bahasa apa yang Anda Gunakan pada Kredit Line}

Kredit harus menyatakan secara akurat mengenai peran Anda dalam proyek. Anda tidak boleh menyatakan bahwa Anda telah membuat sebuah elemen yang sebenarnya tidak Anda buat, seperti foto atau ilustrasi. Akan lebih efektif jika Anda tidak hanya menyertakan nama, yaitu "Desain oleh Nama," tetapi sertakan juga alamat website Anda. Jika alamat situs Anda juga merupakan nama perusahaan atau nama lengkap Anda, orang bisa berhubungan langsung dengan Anda jika Anda menyertakan "Design by yoursite.com." Dengan menggunakan website Anda, orang lain bisa segera melihat portofolio dan menghubungi Anda. Jika anda tidak atau tidak dapat memasukkan alamat situs Anda, pastikan Anda telah berusaha keras untuk meningkatkan hasil pencarian Google Anda (dan mesin 
pencari lainnya). Dengan cara ini, jika seseorang mencari nama Anda dalam google, mereka masih dapat menemukan Anda.

\section{Di Mana Meletakkan Kredit Line Desain Grafis Anda}

Kredit line tidak boleh terlalu menonjol pada halaman. Sebaliknya, kredit itu sebaiknya hampir-hampir tak terlihat pada desain, tetapi juga masih dapat terlihat. Dalam hal ini, pekerjaan Anda adalah mendesain sesuatu untuk klien, bukan untuk mempromosikan diri Anda sendiri. Jika klien telah bersedia untuk menyertakan line Anda, gunakan font berukuran kecil (seperti 6 atau 8pt) dan letakkan line pada tepi halaman atau digabungkan ke dalam elemen desain lain. Untuk web design, umumnya Anda dapat meletakkan kredit Anda pada bagian bawah desain, sebaiknya di setiap halaman.

\section{Saya Sudah Meletakkan Kredit Line Saya, Lalu Apa Lagi?}

Jika Anda meletakkan alamat website Anda pada desain, hal itu akan melaksanakan fungsinya sendiri. Jika kreditnya adalah nama Anda atau nama perusahaan Anda, pastikan dengan sopan untuk mengingatkan klien bahwa Anda selalu menanti pekerjaan selanjutnya (jika memang Anda begitu) dan akan menghargai setiap arahan.

\section{Portofolio}

Jika seseorang akan memberikan nama Anda pada calon klien, akan lebih baik jika mereka memiliki hal lain yang disertakan yang bisa menunjukkan hasil kerja Anda. Dalam hal ini, portofolio website bisa jadi yang paling efektif, karena link merupakan hal yang bisa dengan mudah disertakan dalam email. Jika waktu atau anggaran Anda terbatas, pertimbangkan untuk menciptakan sebuah PDF portofolio yang dapat dilampirkan ke email.

\section{Jenis Portofolio Desain Grafis}

Jika Anda sedang berusaha melakukan terobosan dalam bidang desain grafis, memiliki portofolio yang solid merupakan hal yang sangat penting. Jika Anda sedang berburu pekerjaan, portofolio Anda adalah hal yang akan dilihat perusahaan untuk memutuskan apakah akan memberikan kesempatan wawancara pada Anda atau tidak. Jika Anda merintis bisnis freelance, calon klien akan membandingkan portofolio Anda dengan yang lain. Ada beberapa pilihan atas jenis-jenis portofolio apa saja yang harus dibuat, yang mana masing-masing memiliki kelebihan dan kekurangannya sendiri.

\section{Website}

Portofolio online mungkin adalah jenis yang paling populer saat ini. Sebagai seorang desainer grafis, beberapa orang bahkan akan menganggap anda harus memiliki sebuah website. Jika fokus Anda adalah web desain, portofolio online adalah yang jadi pilihan Anda, karena berperan sebagai contoh hasil kerja Anda.

Kelebihan website adalah: mudah untuk dikirim, karena hanya sebuah link, dapat memberikan pandangan mengenai kepribadian Anda, dan memungkinkan adanya presentasi interaktif atas hasil karya Anda. Sedangkan kekurangannya adalah: paling menyita waktu saat membuatnya, kesulitan mengenai perbedaan tampilan dan cara kerja dari komputer ke komputer, memerlukan pengetahuan teknis untuk mengesetnya, mahal menyewa seseorang untuk membuatkannya, dan anda harus membayar domain nama dan web hosting bulanan. 
Membuat portofolio dalam bentuk PDF menjadi semakin populer. Dengan menggunakan Acrobat, beberapa halaman PDF dapat dibuat dari layout yang diciptakan dalam sebuah program software grafis (seperti InDesign atau Photoshop). Hasilnya akan berupa karya bermodel brosur yang menunjukkan contoh hasil kerja Anda dengan deskripsi proyek dan informasi terkait.

Kelebihan portofolio dalam bentuk PDF adalah mudah di kirimkan lewat email, kontrol atas layout tanpa perlu khawatir tentang masalah web dan browser, PDF itu sendiri berperan sebagai contoh layout dan keterampilan tipografi Anda, Dapat dicetak dengan hasil tetap, dan dibuat relatif cepat dan gratis. Ada pun kekurangan portofolio bentuk PDF adalah bergantung pada pengguna apakah mau menyimpan dan membuka file, dan kurang efektif untuk menampilkan proyek web desain.

\section{Portofolio Klasik}

Portofolio klasik, buku asli dengan berbagai ukuran dengan contoh cetak hasil kerja Anda, masih saja bisa digunakan di "dunia digital" saat ini. Ada beberapa cara untuk menyajikan portofolio seperti ini, mulai dari menempatkan cetakan pada buku setengah jadi dengan memberi penutup, sampai membuatnya sesuai pesanan Anda, buku yang dijilid. Kelebihan portofolio klasik adalah mampu menunjukkan hasil karya Anda pada format yang sebenarnya, yaitu format jadi; baik untuk menampilkan desain cetak; bisa dibawa ke sebuah pertemuan dan ditampilkan tanpa komputer. Sedangkan kekurangan portofolio klasik adalah harus dikirimkan melalui pos atau secara langsung, dan jika Anda meninggalkannya pada calon klien atau pemberi kerja, Anda tidak akan punya portofolio lagi

Pada akhirnya, jenis portofolio yang Anda pilih tergantung pada anggaran Anda, tersedianya waktu dan jenis pekerjaan. Untuk web designer, tak ada lagi yang lebih baik dari portofolio online. Jika Anda tidak memiliki waktu atau anggaran untuk membuat sebuah situs web sekarang, Anda harus memiliki setidaknya portofolio berbentuk PDF sehingga Anda memiliki sesuatu untuk dikirim lewat email. Portofolio klasik adalah hal yang cocok untuk dibawa ke sebuah pertemuan dan untuk memamerkan karya cetak terbaik Anda. Karena portofolio adalah suatu kunci pemasaran, hal ini harus digarap dengan serius, dan kombinasi dari pilihan-pilihan di atas mungkin bisa jadi pilihan yang tepat untuk mendapatkan pekerjaan atau klien impian Anda.

\section{PENUTUP}

"Starting your own business require more than just business sense. It takes a hell a lot of creativity!” (Makki, 2004). Kalimat ini menyatakan bahwa dibutuhkan kreativitas yang sangat luar biasa agar kita berhasil dalam dunia bisnisi desain grafis. Media yang baru diutarakan di atas tadi adalah hanya dasar pijakan. Ucapan senada dilontarkan oleh Waringin (2008) “Bagaimana meningkatkan kekayaan Anda hingga 2000\% dalam waktu 6 bulan / kurang dengan marketing”" jawabannya sekali lagi "It takes a hell a lot of creativity!”

\section{DAFTAR PUSTAKA}

Makki, S. (2004). Entrepreneurship For Graphic Designers, Pozmo Creative Management, 8 April, 2004

Waringin, T. D. (2008). Marketing Revolution, Jakarta: Gramedia Pustaka Utama. 